\title{
THE POSSIBLE ROLE OF RENALASE ENZYME IN CARDIOVASCULAR COMPLICATIONS IN CHRONIC KIDNEY DISEASE PATIENTS
}

\author{
ZAINAB A A AL-SHAMMA* \\ Department of Clinical Pharmacy and Therapeutics, Baghdad College of Pharmacy, Baghdad, Iraq. Email: z.alshamma@gmail.com
}

Received: 09 October 2017, Revised and Accepted: 20 November 2017

\begin{abstract}
Objective: The objective of this research was to study the possible role of renalase in the controlling blood pressure (BP) in patients with different stages of chronic kidney diseases (CKD) to decrease the incidents of cardiovascular disease in these patients.

Methods: The serum levels of renalase were determined by enzyme-linked immune sorbent assay (ELISA) methods in 68 non-diabetic CKD patients in different stages (2-5). Fifty healthy control subjects were included in this study. Renalase high-sensitive C-reactive protein and Cystatin-C were measured by ELISA which is included first incubating the test serum in an antigen-coated polystyrene plate, then enzyme-labeled anti-immunoglobulin is added and the enzyme then remaining in plate after washing provides a measure of the amount of specific antibody in the serum, and in the final step, a substance is added that the enzyme can convert to some detectable signal, most commonly a color change in a chemical substrate.
\end{abstract}

Results: There were a significant difference between serum levels of renalase, in CKD patients stage 5, and CKD patients $2-3$ stage than in their healthy control group $(\mathrm{p}<0.05)$, in addition to a significant difference in renalase level between CKD stage, 2-3 and stage 5 ( $\mathrm{p}<0.05$ ). There was a significant positive correlation between serum renalase with systolic BP $(\mathrm{p}<0.05)$ in CKD patients stage 5 . In addition, there was a significant negative correlation between the serum renalase and estimated glomerular filtration rate $(\mathrm{p}<0.05)$ in both groups.

Conclusions: The main conclusion of the study was the positive significant correlation with systolic BP in CKD patients (stage 5). In addition, the serum renalase levels were elevated according the CKD stage in patients with CKD in different stages (2-5) and it increased with the deterioration of renal function.

Keywords: Renalase, Chronic kidney disease, Estimated glomerular filtration rate, Creatinine, Cystatin-C, Blood pressure.

(C) 2018 The Authors. Published by Innovare Academic Sciences Pvt Ltd. This is an open access article under the CC BY license (http://creativecommons. org/licenses/by/4. 0/) DOI: http://dx.doi.org/10.22159/ajpcr.2018.v11i2.22778

\section{INTRODUCTION}

Hypertension is the most common comorbidity in chronic kidney disease (CKD) patients across different stages (1-5), who are on dialysis. To reduce cardiovascular mortality, the control of blood pressure (BP) of those patients is considered as an important target. There are complex relationships between the elevated BP and cardiovascular mortality in patients with end-stage renal disease (ESRD) due to vascular abnormalities and high prevalence of comorbid conditions [1,2]. The cardiovascular disease (CVD) rate is about 6-10 times higher in dialysis patients than in those who are not undergoing dialysis $[3,4]$. The major established vascular risk factors, for example, hypertension, diabetes, and dyslipidemia occur more frequently and are more severe in those with a low glomerular filtration rate [5]. Renalase and its possible role were first described by $\mathrm{Xu}$ et al., in 2005. It is a member of flavoprotein superfamily, including oxides and monoamine oxidase enzyme. The renalase gene is located on chromosome 10 at q23.33. It contains seven exons and has two transcription variants (1 and 2) according to information available in the GenB. The calculated molecular mass of human renalase is approximately $38 \mathrm{kDa}$. An essential cofactor for its stability and monoamine oxidase (MAO) activity is flavin adenine dinucleotide (FAD) because it has a FAD-binding domain [6,7]. The kidney is considered as the major human secretion sit of renalase, and it is most abundant in the proximal tubules. It is suggested that renalase protein in the proximal tubules is secreted by the basolateral membrane into the circulation where it acts on its substrates, so accomplishing the regulation of catecholamine homeostasis at a systemic level [6]. Renalase is secreted into the blood, and its' levels are regulated by three key factors: Renal function, renal perfusion, and catecholamine level $[5,8]$. Many recent studies in human subjects concluded that plasma renalase levels are negatively correlated with renal function [9-11]. Renalase is also detectable in the heart, skeletal muscle, and small intestine. According to the studies which suggested that renalase is secreted by renal cells since it was detected in both plasma and urine of healthy individuals $[12,13]$. Expression of renalase in peripheral nerves, adrenals, endothelium, and the central nervous system, as well as in adipose tissues, was detected both in 12.5-day-old rat embryo, and more recently, in humans $[12,14]$. The decrease in BP by $25 \%$ as well as a decrease in heart rate and cardiac contractility are the main actions of renalase [6]. According to the study of $\mathrm{Wu}$ et al., these effects occurred when it was administrated intravenously to rats and lasted for minutes and were dose-dependent, showing no difference between the wild-type mouse and renewals knockout mouse. The latter had hypertension, tachycardia, and catecholamine levels higher than the wild-type animal, therefore the knock-out mouse was reported to be more susceptible to myocardial ischemia [15]. It was also found by Li et al. 2008 that renalase deficiency worsened myocardial damage during acute ischemia and the use of the recombinant renalase as treatment could ameliorate cardiac injury [12].

The aim of the study is to evaluate the possible role of renalase in the controlling BP in patients with different stages of CKDsto decrease the incidents of CVD in these patients.

\section{SUBJECTS AND METHODS}

\section{Subjects}

This study included patients with CKD $(n=68)$ (34 females, 34 males) in stage $2-5$. 
The range of age was between 30 and 60 years. They were from kidney disease and transplantation unit at Baghdad Teaching Hospital during the period from September 2015 to March 2016. The study also included apparently healthy control subjects $(n=50)$. Thirty-five controls (17 males and 18 females) from the original 50 controls were chosen to match with CKD patients (stage 2-3) in regard to age and BMI, and 33 controls ( 16 males and 17 females) from the original 50 controls were chosen to match with the CKD patients (stage 5) in regard to age and body mass index (BMI). Exclusion criteria were diabetic chronic kidney failure patients. All control subjects are non-smoker and non-alcoholic. All procedures on human subjects included in this research were performed after approval from the Ethics Committee of researches in the Baghdad College of Pharmacy/Iraq (No 2847 in 26/12/2016).

\section{Methods}

About $10 \mathrm{ml}$ of fasting venous blood were withdrawn from both patients (pre-hemodialysis) and controls. The blood sample was collected in a plain tube and centrifuged for $15 \mathrm{~min}$ at $3000 \mathrm{rpm}$ after being allowed to clot at the room temperature for $30 \mathrm{~min}$. The separated serum was divided into aliquots and stored frozen at $-20^{\circ} \mathrm{C}$ to be used later for renalase (Cusabio, China), high-sensitive C-reactive protein (hsCRP) (Demeditec Diagnostics, Germany), and cystatin-C (Cusabio, China) determination by enzyme-linked immune sorbent assay (ELISA). While blood glucose, lipid profile, urea, and creatinine analysis were done immediately after separation of the serum by spectrophotometric method by SPECORD 40 (Analytik Jena, Germany). The quantitative determination of glomerular filtration rate is calculated by CKD EPI Calculator - four variables MDRD CKD EPI equation with SI units using standardized serum creatinine, age, race, gender, white, or other race male [16]. Body mass index was calculated as body weight (in $\mathrm{kg} / \mathrm{Sq}$ height (meter) [17].

\section{Statistical study}

All values were expressed as mean \pm standard deviation. All statistical analysis was performed using the Statistical Package for the Social Sciences (SPSS version 23.0). Independent Student's t-test was performed to assess differences between two means. The Pearson correlation coefficient was used to determine the correlation between quantitative data. $\mathrm{p}<0.05$ was considered to be statistically significant.

\section{RESULTS AND DISCUSSION}

In CKD patients (stage 5), there are complex relationships between elevated BP and cardiovascular mortality, which leads to the high prevalence of comorbid conditions and underlying vascular abnormalities [18]. Two studies concluded that the rate of CVD in dialysis patients is higher than in dialysis-free patients $[2,19]$.

The present study showed that serum renalase level in CKD patients (stage 5) was higher than in healthy controls $(101.6 \pm 37.6$ vs. $48 \pm 5.9)$, and there were significant differences in serum cystatin-C, hs-CRP, $\mathrm{BP}$, urea, creatinine, and estimated glomerular filtration rate (eGFR) between CKD patients (stage 5) and healthy control as presented in
Table 1. According to two previous studies, the three main key factors that are responsible for the regulation of renalase blood level are the renal perfusion, renal function, and catecholamine level. There was also a direct relationship between renalase, glomerular filtration rate, and kidney mass, resulting in marked renalase deficiency in CKD patients (stage 5) $[12,20]$. On the other hand, there are many recent studies that reported a negative relationship between renalase level and renal function, with the result that renalase level is markedly increased in CKD patients (stage 5) $[21,22]$. One of these studies showed that the serum renalase level was 4 times higher in 34 CKD patients (stage 5) than in 20 healthy controls [22]. Similarly, Zbroch et al. (2012) in their study showed that the serum renalase level was higher in $104 \mathrm{CKD}$ patients (stage 5) than in healthy volunteers [21]. The present study likewise showed a strong negative correlation between serum renalase and eGFR $(\mathrm{r}=-0.51, \mathrm{p}<0.001)$ and strong positive correlation with renal function as assessed by cystatin- $\mathrm{C}(\mathrm{r}=0.37, \mathrm{p}<0.05)$ as shown in Figs. 1 and 2, respectively, and serum creatinine ( $\mathrm{r}=0.54, \mathrm{p}<0.01)$, as in Table 2 , which are the strongest predictors of renalase serum levels. The present study likewise showed a strong negative correlation between serum renalase and eGFR $(\mathrm{r}=-0.51, \mathrm{p}<0.001)$, strong positive correlation with

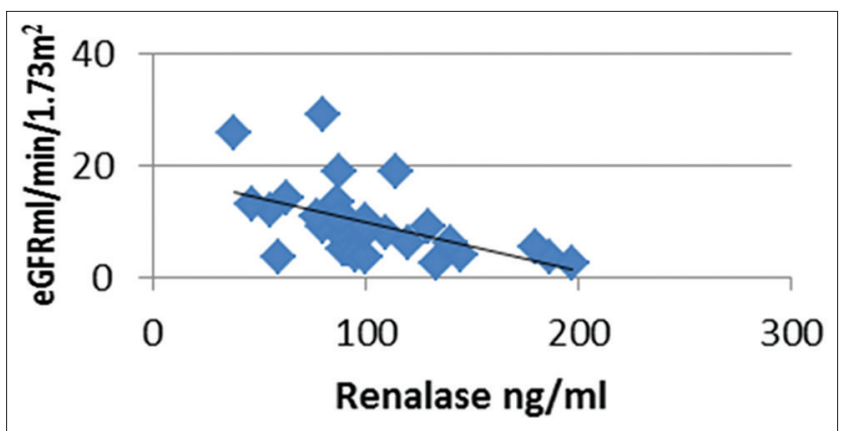

Fig. 1: Correlation between serum renalase and estimated glomerular filtration rate $(r=-0.51, p<0.01)$ in chronic kidney disease patients (stage 5 )

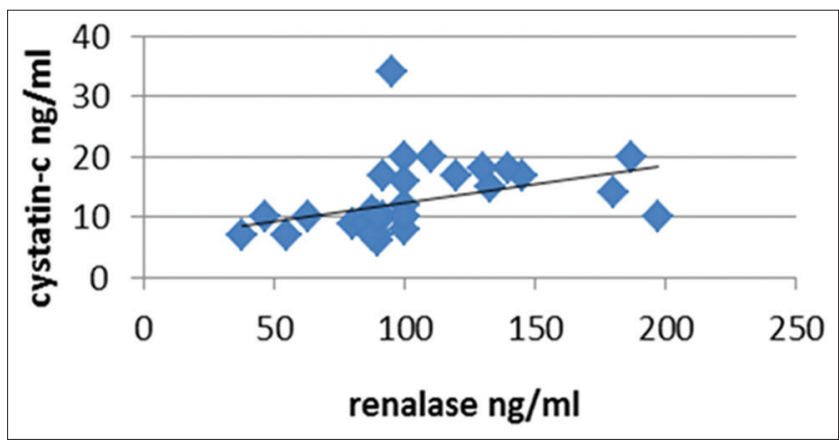

Fig. 2: Correlation between serum renalase and cystatin-c $(r=0.37, p<0.05)$ in chronic kidney disease patients (stage 5 )

Table 1: Comparison between serum variables in CKD patients (stage 5) and their controls

\begin{tabular}{|c|c|c|c|}
\hline Parameter & CKD (stage 5$)^{\alpha}(n=35)$ & $\operatorname{Control}^{\alpha}(n=33)$ & p value \\
\hline Age (year) & $43.4 \pm 14.2$ & $40.8 \pm 13.5$ & 0.76 \\
\hline Body mass index $\left(\mathrm{kg} / \mathrm{m}^{2}\right)$ & $26.1 \pm 2.3$ & $26.2 \pm 3.4$ & 0.94 \\
\hline Renalase $(\mathrm{ng} / \mathrm{ml})$ & $103.4 \pm 36.3$ & $48.8 \pm 5.7$ & $1.1 \mathrm{E}-09^{* *}$ \\
\hline hs-CRP $(\mu \mathrm{g} / \mathrm{ml})$ & $8.4 \pm 2.3$ & $1.2 \pm 0.67$ & $2.0 \mathrm{E}-16^{* *}$ \\
\hline Cystatin-C (ng/ml) & $12.6 \pm 5.8$ & $5.1 \pm 1.4$ & $0.002^{*}$ \\
\hline $\mathrm{eGFR}\left(\mathrm{mL} / \mathrm{min} / 1.73 \mathrm{~m}^{2}\right)$ & $9.65 \pm 6.3$ & $126.2 \pm 33.7$ & $1.0 \mathrm{E}-17^{* *}$ \\
\hline $\mathrm{BP}(\mathrm{mmHg})$ & $141 / 86 \pm 4.3 / 5.1$ & $132 / 77 \pm 3 / 3.7$ & $8.1 \mathrm{E}-18^{* *} / 1.2 \mathrm{E}-10^{* *}$ \\
\hline Urea (m.mol/l) & $54.6 \pm 24.2$ & $10.4 \pm 1.7$ & $1.3 \mathrm{E}-11^{* *}$ \\
\hline Creatinine $(\mu \mathrm{mol} / \mathrm{l})$ & $751.4 \pm 397.8$ & $68 \pm 10.6$ & $4.1 \mathrm{E}-11^{* *}$ \\
\hline
\end{tabular}

${ }^{\alpha}$ Mean \pm SD, ${ }^{*} \mathrm{p}<0.001$ significant, ${ }^{* *} \mathrm{p}<0.0001$ highly significant. CKD: Chronic kidney disease, hs-CRP: High-sensitive C-reactive protein, eGFR: Estimated glomerular filtration rate, BP: Blood pressure, FBS: Fasting blood sugar, SD: Standard deviation 
renal function as assessed by cystatin- $\mathrm{C}(\mathrm{r}=0.37, \mathrm{p}<0.05)$ as shown in Figs. 1 and 2, respectively, and significant positive correlation with both serum creatinine $(\mathrm{r}=0.54, \mathrm{p}<0.01)$, and blood urea $(\mathrm{r}=0.5, \mathrm{p}<0.0001)$, as shown in Table 2 which are the strongest predictors of renalase serum levels. The possible cause of the significant elevation of renalase in hemodialysis patients is the higher sympathetic nervous system activity and much lower renalase clearance in these patients [6]. This suggests the presence of a strong correlation between renalase level and renal function. This is confirmed by the correlations that are mentioned above, which are the main biochemical parameters that reflect the renal function.

In addition, the present study showed the significant differences in renalase level, hsCRP, cystatin-C, urea, creatinine, and eGFR between CKD patients (stage 2-3) and a control group as presented in Table 3. Even more interesting, there was a significant negative correlation between renalase and eGFR in CKD patients (stage 2-3), as shown in Fig. 3, and a significant positive correlation with both serum creatinine and cystatin-C as shown in Figs. 4 and 5, respectively. The results showed a significant difference in renalase level between CKD patients (stage 5) and CKD patients (stages 2-3), as shown in Table 4, which coincided with Gluba-Brzózka et al. 2014 and Cerqueira et al. 2015 in their studies indicated that the renalase level in CKD patients (stage 5) was significantly higher than in CKD patients (stages 2-3), indicating that renalase level depends on the degree of renal function impairment and the rate of renal clearance of renalase, which depends on the eGFR $[22,23]$. One of these recent studies showed that the

Table 2: The correlation between serum renalase and urea, diastolic blood pressure in CKD patients (stage 5)

\begin{tabular}{lll}
\hline Parameters & r value & p value \\
\hline Renalase and creatinine & 0.54 & $<0.01$ \\
Renalase and urea & 0.50 & $<0.05$ \\
Renalase and diastolic & 0.31 & $>0.05$ \\
\hline CKD: Chronic kidney disease & &
\end{tabular}

renalase level depends on the CKD stage, and there was a significant higher renalase level in CKD patients (stage 5) than in patients with CKD (stage 1-3) and strong negative correlation with eGFR [22], while $\mathrm{Xu}$ et al. (2005) in their study concluded that the renalase plasma concentration is markedly reduced in patients with ESRD, as

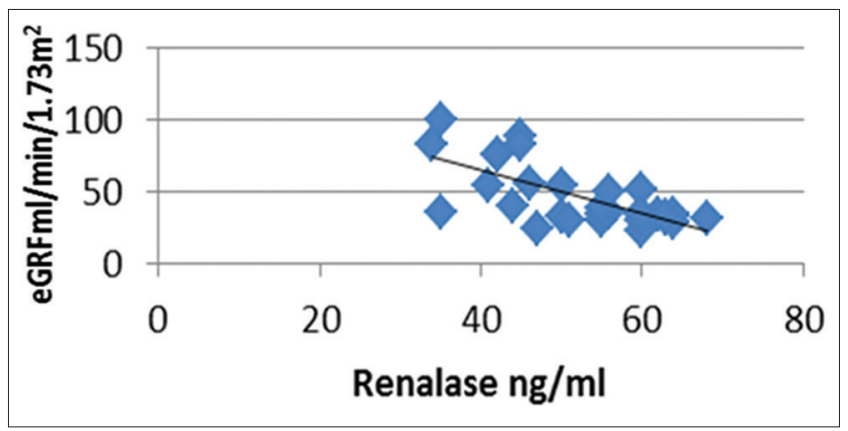

Fig. 3: Correlation between serum renalase and estimated glomerular filtration rate $(r=-0.68, p<0.01)$ in chronic kidney disease patients (2-3 stages)

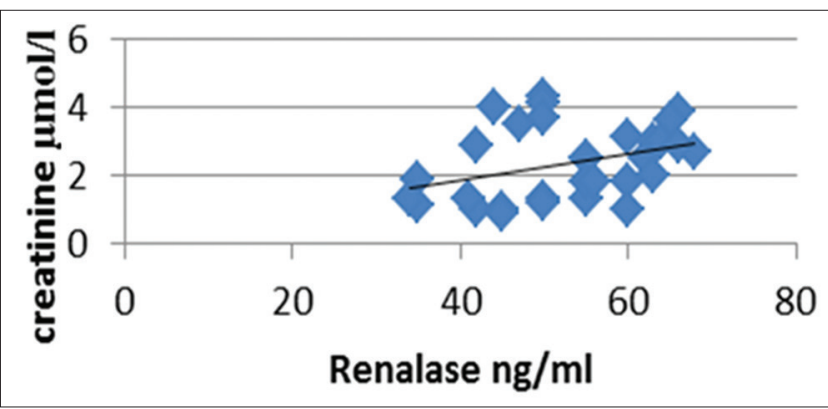

Fig. 4: Correlation between serum renalase and creatinine $(r=0.36, p<0.05)$ in chronic kidney disease patients $(2-3$ stages $)$

Table 3: Comparison between serum variables in patients with CKD and their controls as mean \pm SD

\begin{tabular}{|c|c|c|c|}
\hline Parameter & CKD (stage 2-3) ${ }^{\alpha}(n=33)$ & $\operatorname{Control}^{\alpha}(n=35)$ & p value \\
\hline Age (year) & $52.3 \pm 9.3$ & $48.3 \pm 7.1$ & 0.062 \\
\hline Body mass index $\left(\mathrm{kg} / \mathrm{m}^{2}\right)$ & $28 \pm 2.0$ & $27 \pm 2.3$ & 0.061 \\
\hline Renalase (ng/ml) & $53 \pm 9.9$ & $48.7 \pm 5.9$ & $0.044^{*}$ \\
\hline $\operatorname{hsCRP}(\mu \mathrm{g} / \mathrm{ml})$ & $5.8 \pm 3.2$ & $1.3 \pm 0.66$ & $4.0 \mathrm{E}-09^{* *}$ \\
\hline Cystatin-C (ng/ml) & $8 \pm 3.1$ & $4.9 \pm 1.3$ & $1.3 \mathrm{E}-05^{* *}$ \\
\hline eGFR (mL/min $\left./ 1.73 \mathrm{~m}^{2}\right)$ & $42 \pm 24$ & $125 \pm 32$ & $3.2 \mathrm{E}-15^{* *}$ \\
\hline $\mathrm{BP}(\mathrm{mmHg})$ & $138 / 80 \pm 4.9 / 13.7$ & $133 / 78 \pm 3.5 / 7.5$ & $3.9 \mathrm{E}-07^{* *} / 1.5 \mathrm{E}-09^{* *}$ \\
\hline Urea (m.mol/l) & $24.5 \pm 5.8$ & $10.8 \pm 1.3$ & $2.6 \mathrm{E}-15^{* *}$ \\
\hline Creatinine $(\mu \mathrm{mol} / \mathrm{l})$ & $212 \pm 88.4$ & $67.1 \pm 10.6$ & $1.3 \mathrm{E}-09 * *$ \\
\hline
\end{tabular}

${ }^{a}$ Mean \pm SD, ${ }^{*} \mathrm{p}<0.05$ significant, ${ }^{* *} p<0.0001$ highly significant. CKD: Chronic kidney disease, hs-CRP: High-sensitive C-reactive protein, eGFR: Estimated glomerular filtration rate, BP: Blood pressure, FBS: Fasting blood sugar, SD: Standard deviation

Table 4: Comparison between serum variables in CKD patients (stage 5) and CKD patients (stage 2-3)

\begin{tabular}{lll}
\hline Parameter & CKD (stage 5) ${ }^{\text {a }}$ (n=35) & p value \\
\hline Age (year) & $43.4 \pm 14.2$ & CKD (stage 2-3) ${ }^{\text {a }}(\mathbf{n}=33)$ \\
Body mass index $\left(\mathrm{kg} / \mathrm{m}^{2}\right)$ & $26.1 \pm 2.3$ & $52.4 \pm 11.8$ \\
Renalase $(\mathrm{ng} / \mathrm{ml})$ & $103.4 \pm 36.3$ & $28 \pm 2.0$ \\
hs-CRP $(\mu \mathrm{gg} / \mathrm{ml})$ & $8.4 \pm 2.3$ & $53 \pm 9.9$ \\
Cystatin-C $(\mathrm{ng} / \mathrm{ml})$ & $12.6 \pm 5.8$ & $5.8 \pm 3.2$ \\
eGFR $\left(\mathrm{mL} / \mathrm{min} / 1.73 \mathrm{~m}^{2}\right)$ & $9.65 \pm 6.3$ & $8 \pm 3.1$ \\
BP $(\mathrm{mm} \mathrm{Hg})$ & $141 / 86 \pm 4.3 / 5.1$ & $45 \pm 21$ \\
FBS $(\mathrm{m} . \mathrm{mol} / \mathrm{l})$ & $5.6 \pm 0.71$ & $138 / 80 \pm 4.9 / 13.7$ \\
Urea $(\mathrm{m} . \mathrm{mol} / \mathrm{l})$ & $54.6 \pm 24.2$ & $5.4 \pm 0.81$ \\
Creatinine $(\mu \mathrm{mol} / \mathrm{l})$ & $751.4 \pm 397.8$ & $24.5 \pm 5.8$ \\
\hline
\end{tabular}

${ }^{a}$ Mean \pm SD, ${ }^{*}$ p $<0.05$ significant, ${ }^{* *} p<0.0001$ highly significant. CKD: Chronic kidney disease, hs-CRP: High-sensitive C-reactive protein, eGFR: Estimated glomerular filtration rate, BP: Blood pressure, FBS: Fasting blood sugar, SD: Standard deviation 
Table 4: Comparison between serum variables in CKD patients (stage 5) and CKD patients (stage 2-3)

\begin{tabular}{lll}
\hline Parameter & CKD (stage 5) ${ }^{\text {a }}$ (n=35) & p value \\
\hline Age $($ year) & $43.4 \pm 14.2$ & CKD (stage 2-3) ${ }^{\text {a }}(\mathbf{n}=33)$ \\
Body mass index $\left(\mathrm{kg} / \mathrm{m}^{2}\right)$ & $26.1 \pm 2.3$ & $52.4 \pm 11.8$ \\
Renalase $(\mathrm{ng} / \mathrm{ml})$ & $103.4 \pm 36.3$ & $28 \pm 2.0$ \\
hs-CRP $(\mu \mathrm{g} / \mathrm{ml})$ & $8.4 \pm 2.3$ & $53 \pm 9.9$ \\
Cystatin-C $(\mathrm{ng} / \mathrm{ml})$ & $12.6 \pm 5.8$ & $5.8 \pm 3.2$ \\
eGFR $\left(\mathrm{mL} / \mathrm{min} / 1.73 \mathrm{~m}^{2}\right)$ & $9.65 \pm 6.3$ & $8 \pm 3.1$ \\
BP $(\mathrm{mm} \mathrm{Hg})$ & $141 / 86 \pm 4.3 / 5.1$ & $45 \pm 21$ \\
FBS $(\mathrm{m} . \mathrm{mol} / \mathrm{l})$ & $5.6 \pm 0.71$ & $138 / 80 \pm 4.9 / 13.7$ \\
Urea $(\mathrm{m} . \mathrm{mol} / \mathrm{l})$ & $54.6 \pm 24.2$ & $5.4 \pm 0.81$ \\
Creatinine $(\mu \mathrm{mol} / \mathrm{l})$ & $751.4 \pm 397.8$ & $24.5 \pm 5.8$ \\
\hline
\end{tabular}

${ }^{a}$ Mean \pm SD, ${ }^{*} \mathrm{p}<0.05$ significant, ${ }^{* *} p<0.0001$ highly significant. CKD: Chronic kidney disease, hs-CRP: High-sensitive C-reactive protein, eGFR: Estimated glomerular filtration rate, BP: Blood pressure, FBS: Fasting blood sugar, SD: Standard deviation

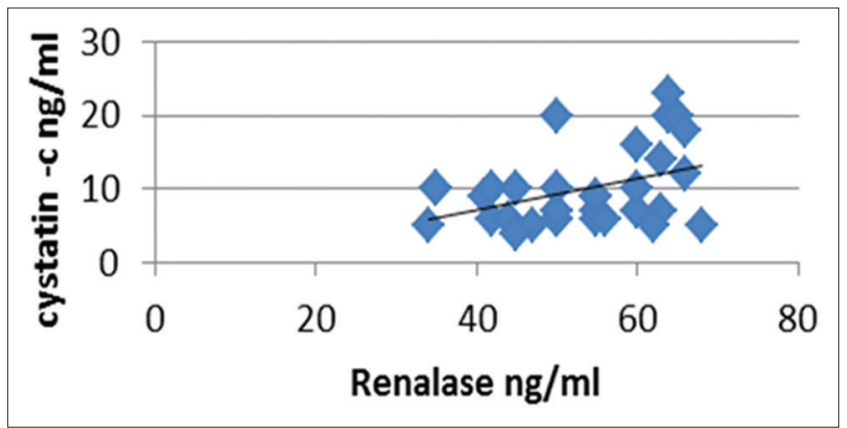

Fig. 5: Correlation between serum renalase and cystatin- $\mathrm{C}(\mathrm{r}=0.4$, $\mathbf{p}<0.05)$ in chronic kidney disease patients $(2-3$ stages $)$

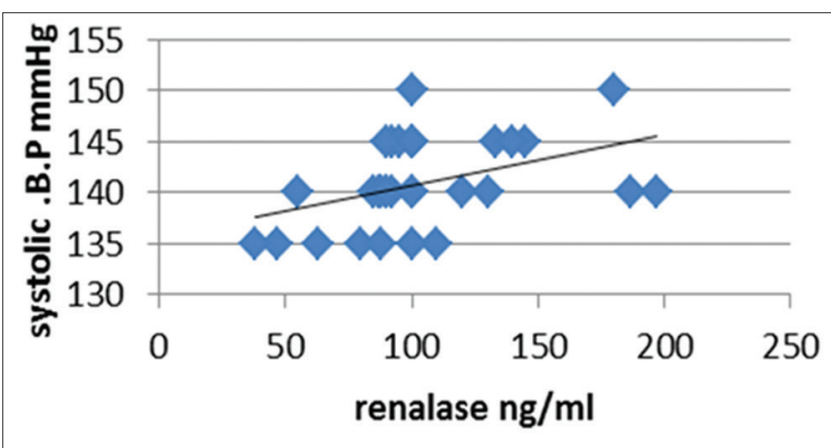

Fig. 6: Correlation between serum renalase and systolic blood pressure $(r=0.42, p<0.05)$ in chronic kidney disease patients (stage 5)

compared with healthy subjects [6]. In the present study, there was a significant positive correlation between serum renalase and systolic $\mathrm{BP}$ in all $35 \mathrm{CKD}$ patients (stage 5) ( $\mathrm{r}=0.42, \mathrm{p}<0.05)$ as in Fig. 6 and non-significant correlation with diastolic BP $(r=0.31, p>0.05)$ as in Table 2. These results agreed to a recent study, which showed the role of renalase in the degradation of catecholamine and the regulation of BP and cardiovascular function, in addition to its relationship with renal function biomarkers [9]. In contrast, many recent studies concluded that the elevated renalase levels in hemodialysis patients may be due to impaired renal function only [24-26]. There are contradictory data about serum renalase because of low activity and high levels revealed in hypertensive patients with CKD [27]. Sotonica et al. (2015) in their study showed no significant correlation between renalase activity and BP in both normotensive and hypertensive hemodialysis patients [26]. While Wang et al. 2015 in their recent study showed a positive relationship between renalase level with both systolic and diastolic BP, in addition to significant higher renalase level in CKD patients (stage 3-5) than in CKD patients (1-2 stage), indicating that renalase level correlated with both BP regulation and renal function [9].

\section{CONCLUSION}

It could be said that evidence from the present study and previous reports suggest the presence of a role for renalase in the regulation of $B P$. There was a significant increase in serum renalase level in both CKD patients (stage 5) and patients with CKD (stages 2-3) and a significant correlation with main biomarkers of renal function impairment in both groups included in the study for any reason, may be of the causes of cardiovascular complications in such patients. More studies are needed to assess whether there is a relationship between plasma renalase levels, and the increases in the incidence of cardiovascular complications risk in CKD patients in different stages, especially in CKD patients (stage 5) undergoing dialysis treatment to use renalase as a new postulated therapeutic target that can reduce these complications in CKD patients, including the sudden cardiac death in CKD patients (stage 5).

\section{ACKNOWLEDGMENT}

The author gratefully acknowledges Dr. Ihsan A.A Al-shamma FRCP (Edin) for his important commitments. Furthermore, the author recognizes and thanks to Dr. Ala sh. Ali. (FIBMS, FEBTM, FRCP Edin Nephrologist, and transplant physician) for allowing the study, and especially to laboratory staff for their commitment and help on samples collection.

\section{CONFLICT OF INTERESTS}

The author declares that they have no competing of interests

\section{REFERENCES}

1. Dasari P, Konuru V, Venisetty RK. Management of comorbidities in chronic kidney disease: A prospective observational study. Int J Pharm Pharm Sci 2014;6:363-7.

2. Ross L, Banerjee D. Cardiovascular complications of chronic kidney disease. Int J Clin Pract 2013;67:4-5.

3. De Jager DJ, Grootendorst DC, Jager KJ, van Dijk PC, Tomas LM, Ansell D, et al. Cardiovascular and non-cardiovascular mortality among patients starting dialysis. J Am Med Assoc 2009;302:1782-9.

4. Hou F, Jiang J, Chen J, Yu X, Zhou Q, Chen P, et al. China collaborative study on dialysis: A multi-centers cohort study on cardiovascular diseases in patients on maintenance dialysis. BMC Nephrol 2012;13:94.

5. Cannon CP. Mixed dyslipidemia, metabolic syndrome, diabetes mellitus, and cardiovascular disease: Clinical implications. Am J Cardiol 2008;102:5L-9.

6. Xu J, Li G, Wang P, Velazquez H, Yao X, Li Y, et al. Renalase is a novel, soluble monoamine oxidase that regulates cardiac function and blood pressure. J Clin Invest 2005; 115:1275-80.

7. Milani M, Ciriello F, Baroni S, Pandini V, Canevari G, Bolognesi $\mathrm{M}$, et al. FAD-binding site and NADP reactivity in human renalase: A new enzyme involved in blood pressure regulation. $\mathrm{J}$ Mol Biol 2011:411:463-73.

8. Quelhas-Santos J, Soares-Silva I, Fernandes-Cerqueira C, Simões-Silva L, Ferreira I, Carvalho C, et al. Plasma and urine renalase levels and activity during the recovery of renal function in kidney transplant recipients. Exp Biol Med (Maywood) 2014;239:502-8. 
9. Wang F, Li J, Xing T, Xie Y, Wang N. Serum renalase is related to catecholamine levels and renal function. Clin Exp Nephrol 2015;19:92-8

10. Wang F, Xing T, Li J, Bai M, Hu R, Zhao Z, et al. Renalase's expression and distribution in renal tissue and cells. PLoS One 2012;7:e46442.

11. Desir G. Novel insights into the physiology of renalase and its role in hypertension and heart disease. Pediatr Nephrol 2012;27:719-25.

12. Li G, Xu J, Wang P, Velazquez H, Li Y, Wu Y, et al. Catecholamines regulate the activity, secretion, and synthesis of renalase. Circulation 2008; $117: 1277-82$

13. Ghosh SS, Gehr TW, Sica DA, Masilamani S, Ghosh S, Wang R, et al. Effect of renalase inhibition on blood pressure. J Am Soc Nephrol 2006; $17: 208$.

14. Hennebry SC, Eikelis N, Socratous F, Desir G, Lambert G, Schlaich M, et al. Renalase, a novel soluble FAD-dependent protein, is synthesized in the brain and peripheral nerves. Mol Psychiatry 2010;15:234-6.

15. Wu Y, Xu J, Velazquez H, Wang P, Li G, Liu D, et al. Renalase deficiency aggravates ischemic myocardial damage. Kidney Int 2011;79:853-60.

16. Levey AS, Stevens LA, Schmid CH, Zhang YL, Castro AF, Feldman HI, et al. CKD-EPI (Chronic kidney disease epidemiology collaboration) a new equation to estimate glomerular filtration rate. Ann Intern Med 2009;150:604-12.

17. Obesity: Preventing and Managing the Global Epidemic: Report of a WHO Consultation. Geneva: World Health Organization. WHO Technical Report Series No. 894; 2000.

18. Urrutia JD, De Guzman JC, Baygan AV, Baccay EB, Bautista LA. Probability estimation on the risk of mortality of patients with end-stage renal disease. Int J Pharm Pharm Sci 2016;8:1-5.

19. Santos SF, Peixoto AJ. Hypertension in dialysis. Curr Opin Nephrol Hypertens 2005;14:111-8.

20. Zbroch E, Malyszko J, Malyszko JS, Koc-Zorawska E, Mysliwiec M. Renalase, a novel enzyme involved in blood pressure regulation, is related to kidney function but not to blood pressure in hemodialysis patients. Kidney Blood Press Res 2012;35:395-9.

21. Gluba-Brzózka A, Michalska-Kasiczak M, Franczyk-Skóra B, Nocuń M, Banach M, Rysz J. Markers of increased cardiovascular risk in patients with chronic kidney disease. Lipids Health Dis 2014;13:135.

22. Cerqueira A, Santos JQ, Martins S, Dias MS, Pestana M. SP321 renalase, renal function and biomarkers of endothelial dysfunction in chronic kidney disease patients. Nephrol Dial Transplant 2015;30:6-8.

23. Malyszko J, Koc-Zorawska E, Malyszko JS, Kozminski P, Zbroch E, Mysliwiec M, et al. Renalase, stroke, and hypertension in hemodialyzed patients. Ren Fail 2012;34:727-31.

24. Przybylowski P, Malyszko J, Kozlowska S, Malyszko J, Koc-Zorawska E, Mysliwiec M, et al. Serum renalase depends on kidney function but not on blood pressure in heart transplant recipients. Transplant Proc 2011;43:3888-91.

25. Sotonica M, Kiseljakovic E, Hasic S, Jadric R. PP.LB02.27: Is renalase blood pressure regulator in heamodialysis patients? J Hypertens 2015;33:E389.

26. Malyszko J, Koc-Zorawska E, Zorawski M, Kozminski P, Zbroch E, Rysz J, et al. Renalase is removed by the kidneys and during dialysis - Excess related to CKD complications? Curr Vasc Pharmacol 2015;13:134-40. 